\title{
Surgical perception of lower tracheal or carinal resection
}

\author{
Yusuke Sugita $^{1,2}$, Hiroaki Kuroda ${ }^{1,2}$, Katsuhiro Masago ${ }^{1,2}$ \\ ${ }^{1}$ Department of Thoracic Surgery, Aichi Cancer Center Hospital, Nagoya, Japan; ${ }^{2}$ Department of Pathology and Molecular Diagnostics, Aichi \\ Cancer Center Hospital, Aichi, Japan \\ Correspondence to: Hiroaki Kuroda, MD, PhD. Department of Thoracic Surgery, Aichi Cancer Center Hospital, 1-1, Kanokoden, Chikusa-ku, Nagoya \\ 464-8681, Japan. Email: h-kuroda@aichi-cc.jp. \\ Comment on: Chen J, Ang KL, Wang C, et al. Minimally invasive carinal reconstruction using bronchial flap and omental flap reinforcement. Ann \\ Thorac Surg 2021. [Epub ahead of print]. doi: 10.1016/j.athoracsur.2021.06.014.
}

Submitted Sep 03, 2021. Accepted for publication Oct 09, 2021.

doi: $10.21037 /$ tlcr-21-723

View this article at: https://dx.doi.org/10.21037/tlcr-21-723

Circumferential or non-circumferential airway resection with end-to-end anastomosis is the most common strategy for treating thoracic malignancies invading the trachea or carina. Carinal resection and lower tracheal or bronchial sleeve resection are fairly challenging procedures for thoracic surgeons. The perioperative management for these procedures can be complex due to the following reasons: (I) most cases are considered inoperable, and operable cases are very few, if not rare; (II) anatomic tension increases significantly as the length of resection goes beyond $4 \mathrm{~cm}$, leading to an increased rate of postoperative complications and anatomic failure (1); (III) for a relatively large tracheal defect, an endotracheal tube for airway management potentially complicates the surgical field during end-toend anastomosis repair; and (IV) the procedure involves a serious risk of postoperative mortality and morbidity.

Chen $e$ al. reported a case wherein central reconstruction was performed with a bronchial flap and omental flap reinforcement using minimally invasive approaches (2). Following the partial response to neoadjuvant chemotherapy, the right main bronchus was opened distal to the $3.5 \mathrm{~cm} \times$ $3.8 \mathrm{~cm}$ mass of the carina, under bronchoscopic guidance. Notably, the omental flap was harvested in a supine position via a 4-port laparoscopic approach with $\mathrm{CO}_{2}$ insufflation at $12 \mathrm{mmHg}$, and carinal reconstruction was performed using a bronchial flap and omental flap via 3-ports thoracoscopic approach with a maximum $4-5 \mathrm{~cm}$ incision in the left lateral decubitus position. Fortunately, the cuff of the bronchus, including the right upper lobe orifice, bronchus intermedius, and distal left main bronchus, could be preserved. The cuff of the right lobe and bronchus intermedius were sutured to the trachea and the left main bronchus margin. The patient's postoperative course was uneventful and with no evidence of complications or recurrence at the 1-year follow-up. Finally, they concluded that minimally invasive carinal reconstruction with bronchial flap and omental reinforcement after neoadjuvant treatment could be safely performed.

Long-segment circumferential tracheal or carinal resection usually leaves a large central airway defect, and repair through an end-to-end anastomosis is considered unfeasible and risky. In addition, anastomosis of the trachea and bronchus with different calibre is a complicated procedure and might cause ischemia at the junction of the trachea or the bronchus (3). Therefore, performing end-to-end anastomosis to reconstruct long-segment bronchial defects is challenging even for experienced surgeons. Several studies have shown that thoracic surgeons required experience handling more than 4 to 9 cases of bronchial anastomosis until they can complete the procedure in less than 60 minutes $(4,5)$. Nakada et al. suggested that a 3-dimensional thoracic model simulating the bronchus can help thoracic surgeons practice suturing through the actual port site, and confirmation of the optimal angle of the needle and handling of the thread could help avoid string tangling and aid in the quick understanding of surgical pitfalls (6).

To the best of our knowledge, a large retrospective study ( $\mathrm{n}=73$ ) examining the reconstruction of long noncircumferential tracheal or carinal resections with bronchial flaps proposed that airway defects that do not exceed $50 \%$ of the airway circumference are a prerequisite to bronchial flap reconstruction during preoperative evaluation (7). However, 
even under favourable circumstances, the maximum length of tracheal-carinal resections with end-to-end anastomosis is limited and should not exceed approximately $4 \mathrm{~cm}$ (8). For tracheal defects greater than $4 \mathrm{~cm}$, end-to-end anastomosis is believed to be less feasible because of excessive tension (9). Peng et al. reported the effectiveness of reducing the anatomical and longitudinal tension by creating an additional $\mathrm{V}$-shaped trim on the junction of the trachea and bronchial flap technique (7).

Postoperative bronchopleural fistula (BPF) is a serious complication that can affect approximately $5 \%$ of cases $(7,10)$. The following are major risk factors for BPF: (I) perioperative susceptibility for a lung infection; (II) devascularization of anastomosis due to thorough systemic lymph node dissection or complete disruption of bronchial arterial flow; and (III) technical error while suturing. Routine flap coverage of the stump is reportedly crucial and can help prevent dehiscence of the stump because of the enhanced blood supply and can plug leakage into the thoracic space if dehiscence occurs (3). Chen et al. justified using an omental flap harbouring the promotion of healing and neovascularisation to reduce the risk of airway anastomosis complications after neoadjuvant chemotherapy (2). If possible, bronchial arterial preservation is desirable for retaining the arterial flow surrounding the anastomosis. Ishihara et al. reported that bronchial arterial circulation consisted primarily of systemic arterial blood after sleeve lobectomy in dogs with preserved bronchial artery. The bronchial articulation significantly improved in those with preserved bronchial artery than those with pedicled pleural wrap (11).

The simultaneous handling of anastomosis and coverage materials in patients with severe complications can be challenging for thoracic surgeons, even via thoracotomy. Emerging evidence and clinical experience suggest that tracheal or carinal resection via the thoracoscopic approach is a safe and feasible procedure in selected patients $(2,12)$. Hu et al. reported that the visual and mechanical precision provided by robotic tools could facilitate accurate suturing even in confined spaces (13). Jiang et al. introduced no intubation technique for spontaneous ventilation thoracoscopic surgery for tracheal or carinal resection. It provides surgeons with an unobstructed view of the surgical field because the trachea is more flexible, with a wider range of motion during resection and anastomosis, even though urgent intubation is required (14). Finally, the knowledge of 'the recent development of minimally invasive techniques' highlights the future steps in tracheal or carinal resection.

\section{Acknowledgments}

Funding: None.

\section{Footnote}

Provenance and Peer Review: This article was commissioned by the editorial office, Translational Lung Cancer Research. The article did not undergo external peer review.

Conflicts of Interest: All authors have completed the ICMJE uniform disclosure form (available at https://dx.doi. org/10.21037/tlcr-21-723). The authors have no conflicts of interest to declare.

Ethical Statement: The authors are accountable for all aspects of the work in ensuring that questions related to the accuracy or integrity of any part of the work are appropriately investigated and resolved.

Open Access Statement: This is an Open Access article distributed in accordance with the Creative Commons Attribution-NonCommercial-NoDerivs 4.0 International License (CC BY-NC-ND 4.0), which permits the noncommercial replication and distribution of the article with the strict proviso that no changes or edits are made and the original work is properly cited (including links to both the formal publication through the relevant DOI and the license). See: https://creativecommons.org/licenses/by-nc-nd/4.0/.

\section{References}

1. Mulliken JB, Grillo HC. The limits of tracheal resection with primary anastomosis: further anatomical studies in man. J Thorac Cardiovasc Surg 1968;55:418-21.

2. Chen J, Ang KL, Wang C, et al. Minimally invasive carinal reconstruction using bronchial flap and omental flap reinforcement. Ann Thorac Surg 2021. [Epub ahead of print]. doi: 10.1016/j.athoracsur.2021.06.014.

3. Salassa JR, Pearson BW, Payne WS. Gross and microscopical blood supply of the trachea. Ann Thorac Surg 1977;24:100-7.

4. Ma S, Yan T, Liu D, et al. Initial experience of sleeve lobectomy under complete video-assisted thoracic surgery. Asia Pac J Clin Oncol 2018;14:114-9.

5. Shao F, Liu Z, Pan Y, et al. Bronchoplasty using continuous suture in complete monitor view: a suitable method of thoracoscopic sleeve lobectomy for non-small 
cell lung cancer. World J Surg Oncol 2016;14:134.

6. Nakada T, Noda Y, Kato D, et al. Simultaneous TwoDimensional and Three-Dimensional Simulation of Thoracoscopic Sleeve Lobectomy: A Quick Understanding of Pitfalls. Ann Thorac Surg 2020;109:e383-5.

7. Peng Q, Zhang L, Ren Y, et al. Reconstruction of Long Noncircumferential Tracheal or Carinal Resections With Bronchial Flaps. Ann Thorac Surg 2019;108:417-23.

8. Gaissert HA. Primary tracheal tumors. Chest Surg Clin N Am 2003;13:247-56.

9. Chen QK, Jiang GN, Ding JA, et al. Reconstruction of the lower trachea using a pedicled autologous bronchial flap. Ann Thorac Surg 2010;89:e29-30.

10. Shin S, Park JS, Shim YM, et al. Carinal resection and reconstruction in thoracic malignancies. J Surg Oncol 2014;110:239-44.

Cite this article as: Sugita Y, Kuroda H, Masago K. Surgical perception of lower tracheal or carinal resection. Transl Lung Cancer Res 2021;10(11):4310-4312. doi: 10.21037/tlcr-21-723
11. Ishihara T, Nemoto E, Kikuchi K, et al. Does pleural bronchial wrapping improve wound healing in right sleeve lobectomy? J Thorac Cardiovasc Surg 1985;89:665-72.

12. Li J, Wang W, Jiang L, et al. Video-Assisted Thoracic Surgery Resection and Reconstruction of Carina and Trachea for Malignant or Benign Disease in 12 Patients: Three Centers' Experience in China. Ann Thorac Surg 2016;102:295-303.

13. Hu D, Wang Z, Tantai J, et al. Robotic-assisted thoracoscopic resection and reconstruction of the carina. Interact Cardiovasc Thorac Surg 2020;31:912-4.

14. Jiang L, Liu J, Gonzalez-Rivas D, et al. Thoracoscopic surgery for tracheal and carinal resection and reconstruction under spontaneous ventilation. J Thorac Cardiovasc Surg 2018;155:2746-54. 